\title{
Using quality and safety education for nurses principles to enhance foundational nursing courses: Outcomes from an innovative curriculum project
}

\author{
Susan M. McLennon, Barbara Manz Friesth, Sue Lasiter \\ School of Nursing, Indiana University, Indianapolis, USA \\ Correspondence: Susan McLennon. Address: School of Nursing, Indiana University, 1111 Middle Dr., NU W437, \\ Indianapolis, IN 46202. Telephone: 317-278-0459. Email: smclenno@iupui.edu.
}

Received: August 19, 2012

DOI : $10.5430 /$ jnep.v3n4p1

Online Published: December 3, 2012

URL: http://dx.doi.org/10.5430/jnep.v3n4p1

\begin{abstract}
Background: Shortcomings of traditional methods used to prepare undergraduate nursing students for the increasingly complex demands of the current healthcare environment have been cited by national organizations as rationale for the revision of nursing program curricula. In this curriculum project, two undergraduate nursing courses, in which students were simultaneously enrolled, were enhanced to meet emerging national standards for nursing education.
\end{abstract}

Objectives: The aims of this project were to: 1) integrate the didactic and psychomotor skill components of the two courses into congruent modules with a focus on application in complex health care settings, 2) increase the emphasis on self-directed and collaborative learning to prepare students for inter-professional practice, and 3) implement learning experiences that incorporate the knowledge, skills, and attitudes necessary for professional role development.

Methods: Guided by recommendations from the Quality and Safety Education for Nurses project and the American Association of Colleges of Nursing document Essentials for Baccalaureate Education, several enhancements were implemented. First, enhancements were piloted in the fall semester with a small group of students enrolled in the two courses. In the following semester, the full project was implemented for all students $(n=126)$ and course faculty $(n=12)$. Specific strategies included the development of a set of 24 proprietary skills videos, a group cultural competence project, an unfolding case study, and adding clinical situations to support learning in context in the classroom and during psychomotor skills training. Outcomes were evaluated with student and faculty surveys and a faculty focus group. Descriptive statistics were used to summarize survey data and a content analysis was performed on data from the focus group.

Results: Overall, the faculty and students evaluated the curriculum enhancements positively with $57 \%$ to $88 \%$ rating most of the items as "strongly agree" or "agree”. From the focus group, faculty perceived that the enhancements were "more organized...it just flowed", and "it made clinical a little easier. Faculty thought students were "taking more ownership...of their own learning."

Implications and Conclusions: Students and faculty thought that course changes encouraged self-directed learning and successfully merged clinical application with didactic and psychomotor skills classes. These findings may be useful for others planning course changes that enhance self-directed learning, and that want to merge clinical application within the didactic and psychomotor skills classes. Future research to examine changes in student knowledge, skills, and attitudes as a result of educational initiatives, at all levels of the nursing curriculum is recommended. 


\section{Key words}

Curriculum, Education, Undergraduate, Baccalaureate

\section{I ntroduction}

Traditionally, the knowledge and psychomotor skills needed to begin clinical nursing practice were taught to student nurses using lecture and one-to-one return demonstrations in curriculum models that separated knowledge from skill development. The Institute of Medicine ${ }^{[1]}$ identified shortcomings of this method and has called for revised education to better prepare graduates for collaborative practice in an increasingly complex health care environment. The Quality and Safety Education for Nurses (QSEN) ${ }^{[2]}$ initiative has also emphasized incorporating principles of knowledge, skills, and attitudes into nursing education.

To align Indiana University's School of Nursing's (IUSON) two required foundational baccalaureate nursing courses with these national initiatives, course enhancements were developed that integrated knowledge, skills, and attitudes appropriate for beginning students with increased focus on clinical applications. Enhancements included new learning activities that emphasized application to clinical practice and self-directed learning such as case studies, small group work, and independent use of skills videos.

Consistent with national guidelines for preparing nurses for practice, the overall goal of this project was to align the two foundational courses, one focused on didactic content and the other focused on associated psychomotor skills, with emerging national standards for preparing students to practice in a complex, inter-professional health care setting. The specific aims were to: 1) combine the knowledge and skill content from two courses into integrated modules with a focus on application in complex health care settings, 2) initiate self-directed and collaborative learning to better prepare students earlier in the curriculum for clinical practice, and 3) introduce experiences that applied aspects of the clinical environment in the classroom and during the acquisition of psychomotor skills to better integrate knowledge with skills and to foster the development of attitudes important for professional role development.

\section{Literature review}

Because the complexity of nursing care has increased exponentially over the recent decade, there have been concerns about student's preparation for practice ${ }^{[3,4]}$. The current clinical model in which a faculty member oversees 10 nursing students is not sustainable or even desirable in the present health-care environment ${ }^{[5]}$. Two major difficulties have been identified with the traditional models for educating student nurses.

First, there is a risk for mismatch between course objectives and available clinical experiences. McNelis and Ironside ${ }^{[6]}$ reported that a majority of nursing faculty have difficulty matching the requisite clinical experiences with course learning objectives because of limitations and variations within and between the clinical agencies and units. Clinical experiences varied to the extent that intra-individual variation occurred and compounded the difficulties faced by faculty and students to meet learning objectives and educational outcomes. A second limitation with traditional teaching methods is that students have been underprepared for clinical practice. Because of the lack of adequate time for skills practice, there have been weaknesses in new graduates' abilities to apply skills in the work place ${ }^{[7-9]}$.

Alternatives to traditional education approaches have been suggested in the literature. Incorporating independent learning activities that allow additional time to be spent on psychomotor skills practice, and foster self-directed learning, have been found to improve student performance ${ }^{[9]}$. Course enhancements such as case studies and simulated clinical situations using task trainers create reliable learning experiences for students that require decision-making, taking action, and clinical 
judgment ${ }^{[10]}$. Learning experiences that require collaboration are also effective teaching techniques that create a high quality learning environment and help prepare students to interact in clinical settings ${ }^{[11]}$.

\section{Project overview}

Every undergraduate nursing program requires foundational courses to prepare students as beginning level clinicians for a professional practice role. Didactic content is foundational to the development of clinical skills. The two required courses that delivered the content and skills at IUSON were concurrent and placed in the sophomore year. At IUSON, total annual enrollment in these two courses was approximately 290 students (fall $=130$, spring $=130$, summer $=30$ students).

In these courses, students learned theoretical/scientific principles and psychomotor skills, for example, necessary for mobilizing patients, maintaining hygiene, preventing infection, delivering intravenous fluids, and inserting catheters. After mastery of didactic content and the associated psychomotor skills, students were placed in a clinical environment where they began to apply knowledge, skills, and attitudes to patient care. These experiences provided students the opportunity to begin developing professional nursing roles, cultivate nurse-patient relationships, practice communication in a team environment, and engage with confidential medical records. Culture, values, ethics, and regulatory parameters framed the nurse-patient relationship and shaped the professional role, and therefore supportive content in these areas was included as it applied to psychomotor skill acquisition.

Following traditional models of teaching ${ }^{[9]}$, the course content was previously delivered by a faculty member through lectures to large groups of students in a knowledge acquisition course and in small groups of 10 students assigned to a clinical instructor in the School of Nursing Resource Center for Innovations in Clinical Nursing Education (RCICNE) for skills education and acquisition and then to a clinical area. For the psychomotor skills portion, faculty routinely presented commercially licensed skills videos (that were costly and inconsistent with course textbooks), lectured the content needed to teach the skills, and/or demonstrated skills to groups of students, followed by practice time. However, this format left inadequate time for students to practice the psychomotor skills ${ }^{[9]}$. As a result, students felt uncertain about their own abilities while faculty reported that students were inadequately prepared in clinical situations that required performance of basic skills. In addition, because of the large number of students and requisite multiple course sections, delivery of the didactic content did not consistently precede the associated psychomotor skills, requiring more lecture time prior to skills learning. In this traditional model, students were predominately passive recipients of information presented by faculty and learning was evaluated individually with multiple-choice exams and skills testing via return demonstrations in which faculty judged students 'satisfactory' (or not) before they could proceed to clinical settings to care for patients.

\section{Assessment and recommendations}

As a result of an increasing awareness of the need to better prepare nursing students for the complexities of the current health-care environment, a group of nursing faculty members met to discuss necessary course enhancements. The underlying motivation for change included a desire to incorporate material recommended from the QSEN ${ }^{[2]}$ project, the American Association of Colleges of Nursing document, and the Essentials for Baccalaureate Education ${ }^{[12]}$. There was also a growing recognition of "disconnect" between the content delivered in the two courses so that the didactic course content did not consistently match the skills course. Faculty involved in the courses convened a series of six meetings over a 4 month time frame during which information was gathered, data were summarized, and priorities were identified and agreed upon. Information was gathered from a variety of sources including recommendations from the national initiatives to improve undergraduate nursing curricula, student course evaluations, faculty comments from informal small group discussions, results from a Delphi survey ${ }^{[13]}$ of the undergraduate faculty at IUSON, and a review of educational literature.

Ultimately, the following enhancements were recommended: 1) reorganize the content in both courses so that students learned principles and subject material (didactic content) prior to learning the associated psychomotor skills and tasks, 
2) offer additional time for independent student skills practice in the RCICNE, 3) develop a set of proprietary skills videos that could be readily accessed by students and are congruent with course materials and textbooks, 4) incorporate clinical situations to emphasize application to practice and to facilitate a match between learning objectives and available experiences, 5) develop group activities that promote teamwork, and 6) introduce clinical cases in didactic and psychomotor skills experiences to better prepare students for the complexities of an interdisciplinary health care environment and for professional roles that require life-long learning. These six project recommendations were consolidated into three broad aims that were implemented and evaluated.

\section{Guiding framework}

Because of the need to improve quality and safety in health care settings, the Robert Wood Johnson Foundation provided funding for a project to prepare nurses to improve these environments. The QSEN ${ }^{[2]}$ project focused on six specific competencies recommended by the Institute of Medicine (IOM) $\left.{ }^{[1]}: 1\right)$ patient centered care, 2) teamwork and collaboration, 3) evidence-based practice, 4) quality improvement, 5) informatics, and 6) safety. In addition to these competencies, the knowledge, skills and attitudes required for each of the six competencies were also developed for nursing education programs. Barton and colleagues ${ }^{[4]}$ published findings from a national Delphi survey ${ }^{[13]}$ of nursing content experts who offered guidelines for student progression across the curriculum (leveling) to achieve the QSEN competencies ${ }^{[2]}$. For beginning students, specific competencies in the areas of patient-centered care, safety, and informatics were suggested.

The QSEN competencies identified by Barton and colleagues ${ }^{[4]}$ for beginning students guided the course enhancements for this project. In addition, the Essentials for Baccalaureate Education for professional nursing practice from the American Association of Colleges of Nursing (AACN) were used ${ }^{[12]}$. Specific curriculum content identified to add to the two courses was determined from results of the IUSON faculty Delphi survey ${ }^{[13]}$ that was performed to assess the undergraduate curriculum for congruence with recommendations from the AACN document and general areas that were identified included: 1) collaborative practice, 2) gerontological aspects of care and 3) cultural considerations.

\section{Methods}

This curriculum project was undertaken after an assessment of the problem and consulting existing literature for strategy development. The following section outlines specific strategies that were developed. As an added note, many of the competencies were already incorporated elsewhere in the IUSON curriculum and within the two courses. However, the purpose of this project was to enhance the targeted courses.

\subsection{Design and sample}

The project was designed to be completed in one year. Enhancements were planned during summer session and piloted in the fall semester with one section $(n=39)$ and faculty $(n=4)$. The pilot project was evaluated, and recommendations were incorporated. Prior to implementing the full project, all faculty teaching in both courses were oriented to the changes and given a course handbook. The project was fully implemented in all sections ( $\mathrm{n}=126$ students) and faculty $(\mathrm{n}=12)$ in the spring semester.

\subsection{Strategies to integrate courses with emphasis on application}

Content was reorganized by textbook chapter headings which were then ordered to begin with the most basic and progress to more complex knowledge and associated skills. For each topic, objectives for student learning for didactic (classroom) and laboratory (psychomotor skills) were refined. Topics were ordered so that students were exposed to the didactic component prior to skill acquisition. A handbook was developed for faculty teaching the courses that included a course calendar organized by dates and topics. Topics were ordered by week and were divided into sections that contained 
classroom objectives, content outlines, and suggestions for teaching strategies. For each skills laboratory (RCICNE) session there were detailed outlines, behavioral objectives, competencies, suggested teaching strategies, and methods for assessing skill attainment.

Course enhancements included a greater focus on application to health care settings. In both the classroom and the associated psychomotor skills courses, students were introduced to a topic and a corresponding commonly encountered clinical situation. For example, during a classroom session on mobility, students divided into small groups, were given a specific scenario about a patient with an alteration in mobility, and asked to develop a solution that was then discussed with the class as whole. At other times, the class as a group worked through a clinical scenario that was intended to stimulate critical thinking and discussion. Specific scenarios might include patients who are obese, confused, or an older adult with a risk for falls.

Similarly, while practicing skills in the RCICNE, students were encouraged to learn in context using the task trainers to add fidelity. In pre-selected sessions, students were provided patient scenarios prior to entering their practice area. For example, they may have been given the patients name, diagnosis, length of stay, past medical and social history, and other pertinent but basic information. Care was taken not to provide students with advanced clinical information that they were not prepared for, nor to add complex and potential confusing information, but enough to provide some context and heighten awareness, thus fostering the early development of attitudes about their professional roles while integrating knowledge with skills.

There was a greater emphasis placed on patient confidentiality and other safety measures related to the electronic medical record, including accessing, retrieving, and protecting confidential health information. Accurate and timely documentation in the medical record, safe administration of medications and other treatments, and error reporting were also emphasized.

\subsection{Strategies to emphasize self-directed and collaborative learning}

The main strategies implemented to facilitate student self-directed and collaborative learning were the development of proprietary skills videos, addition of blocks of time that the lab was open for independent practice, and assignment of a group cultural competence project.

Topics for development of skills videos were identified by using an anonymous survey administered to faculty asking them to prioritize skills that they thought would be helpful to videotape for use in the foundational courses. Professional videographers were enlisted to ensure a quality product. Volunteer students and faculty were recruited as "actors" who performed the procedures consistent with course textbooks. Skills were storyboarded and videotaped primarily in the RCICNE. Ultimately, a total of 24 skills videos were completed that students were able to view anywhere they could gain access to the internet. During orientation students were provided a schedule of dates and times that the laboratory would be open for practice during the semester. It was explained that additional practice time, outside of scheduled classroom and laboratory hours, would be necessary to attain a satisfactory skill level and progress to clinical areas which encouraged self-directed learning.

A group presentation focused on culture was assigned to foster the development of collaboration and intra-professional practice. This assignment had a dual purpose; to discuss cultural competence and, congruent with the QSEN competencies in Barton et al. ${ }^{[4]}$, to engage in discussions of various health care team members' roles in the healthcare setting.

Students were randomly assigned into small groups at the beginning of the semester and elected a cultural group to investigate. An outline of project expectations and a grading rubric was provided. Students were to briefly describe key cultural characteristics about the population that could influence their health, describe how their own personal beliefs and 
attitudes might influence the type of care provided, and apply knowledge of that particular culture to describe ways that basic nursing care could be adapted to meet specific needs (e.g. hygiene, elimination, pain assessment).

\subsection{Strategies to incorporate knowledge, skills, and attitudes for role development}

The purpose for developing an unfolding case study was to incorporate the overarching goals for the project. The fictitious case was presented via power point and created to unfold weekly over the semester during the classroom experience. Mrs. Esther Smith, a healthy, 83 year old widow who lived alone in a two story house, was introduced to the students early in the semester. Every week a major health event occurred that coincided with the class topic. For example, she sustained a fractured hip from a fall at home that required hospital admission and surgery. Mrs. Smith's story was used as a springboard for class discussions about immobility, pain assessment, comfort measures, and pressure ulcers. The case culminated at the end of the semester with Mrs. Smith’s discharge to a nursing home for rehabilitation.

Another strategy used in the skills laboratory to integrate knowledge, skills, and attitudes for quality care and patient safety were exercises that illustrated potential patient situations. For example, an exercise titled "Find the Safety Errors" was incorporated in which a sample patient hospital room was arranged with numerous safety errors for the students to identify. A number of safety errors were present in the room such as unlocked hospital bed wheels, restraints tied incorrectly, call bell out of reach, spills, and the wrong information on the identification band. Faculty used the scenario in different and creative ways to accomplish the objectives.

\section{Evaluation of the pilot project}

Survey tools were developed and administered to students enrolled in the fall semester pilot project. Questions were designed to assess whether the goals of the project were accomplished, and to what degree. Most of the questions could be answered with response choices that ranged from $5=$ strongly agree, to $1=$ strongly disagree. Space was provided at the end of the survey for additional comments. All student enrolled in the courses were invited to participate via email. The email contained a link to the survey. Participation was voluntary and responses were anonymous. A focus group was held with faculty who participated in the pilot project. Approval of the Institutional Review Board was received and appropriate procedures for the ethical conduct in research, consent, and confidentiality, were followed.

\subsection{Results of the student survey}

Of the 39 students enrolled, 15 participated in the survey, yielding a response rate of $40 \%$. The majority of students strongly agreed or agreed that the classroom content prepared them for the laboratory experiences (87\%), thought that the new skills videos were helpful to learning (87\%), and viewed all or most of the videos (80\%). The students rated the group cultural competence project highly in terms of increasing their knowledge about caring for people from diverse cultures (73\% strongly agreed/agreed). They also found the unfolding case study to be helpful for applying classroom content to clinical (67\% strongly agreed/agreed). Finally, $60 \%$ strongly agreed or agreed that they felt prepared to attend clinical in the following semester.

\subsection{Results of the faculty focus group}

A one-time focus group of three faculty members who had experience teaching both courses before and during the piloted course enhancements was held. The focus group was led by a nurse researcher (SL) with experience in interviewing, qualitative research, and data analysis. After informed consent, a semi-structured interview guide designed to elicit information about faculty experiences and perceptions of the course changes was used to guide the discussion. The discussion was audio-recorded, transcribed verbatim, and checked for accuracy. 
Data were analyzed and coded by two nurse researchers (SM \& SL) with experience in qualitative analysis following recommended methods for content analysis ${ }^{[14,15]}$. Data were hand coded because responses were fairly short and the limited volume of text was manageable in printed copy and making notations in the margins during open coding was easier to accomplish on paper. Consistent with inductive content analysis, each response was broken down into phrases that contained one meaning and labeled as a category. Similar concepts were extracted from the data and were determined by the researchers to be distinct. These concepts were divided into two groups and reported as related to one of two higher order categories. Labels for the concepts were found within the data to support face validity. Exemplars of supporting quotes for the concepts were extracted. All authors analyzed the data and validated the analysis. Final results of the focus group are reported in Table 1.

Table 1. Faculty Focus Group Data $(\mathrm{n}=3)$

\begin{tabular}{|c|c|c|c|}
\hline Main Categories & Sub-categories & Concepts & Supporting Quotes \\
\hline \multirow[t]{5}{*}{$\begin{array}{l}\text { Faculty Perception } \\
\text { of Student Change }\end{array}$} & $\begin{array}{l}\text { Getting what they } \\
\text { need }\end{array}$ & Taking ownership & $\begin{array}{l}\text { "It's that they, the students are taking more from this particular } \\
\text { design ... more ownership of their own learning." }\end{array}$ \\
\hline & & Better prepared & $\begin{array}{l}\text { "They already have that base knowledge, so it's easy for them to } \\
\text { just get in there and want to do it." }\end{array}$ \\
\hline & & $\begin{array}{l}\text { Ease of access to } \\
\text { videos }\end{array}$ & $\begin{array}{l}\text { "More opportunity to view them outside of the school setting, at } \\
\text { their own home and time" }\end{array}$ \\
\hline & & $\begin{array}{l}\text { Eager for real } \\
\text { experiences }\end{array}$ & $\begin{array}{l}\text { "I very much like the slight modification now (a clinical } \\
\text { midway), when they are so eager. They needed the experience, } \\
\text { what it was going to be like in the hospital..." }\end{array}$ \\
\hline & & Simulations & $\begin{array}{l}\text { "Very basic, getting started for the care of the day and basic } \\
\text { assessments, skills that they got to practice on sim man, and it } \\
\text { was very helpful, and they loved that." }\end{array}$ \\
\hline \multirow[t]{6}{*}{$\begin{array}{l}\text { Faculty Perception } \\
\text { of their Roles }\end{array}$} & $\begin{array}{l}\text { The way we } \\
\text { taught then }\end{array}$ & $\begin{array}{l}\text { Struggling to } \\
\text { cover content }\end{array}$ & $\begin{array}{l}\text { "I felt like there were a lot of teaching moments that were missed } \\
\text { because I couldn't spend the time that I needed to present } \\
\text { material and for the students to acquire the information" }\end{array}$ \\
\hline & & Disorganized & "We had various topics and we jumped from place to place" \\
\hline & The new way & $\begin{array}{l}\text { The way we teach } \\
\text { now }\end{array}$ & "[It was] more organized, better for the students. It just flowed." \\
\hline & & Skill acquisition & $\begin{array}{l}\text { "With that didactic already being done, now we can teach the } \\
\text { hands on part of it, and then they do it." }\end{array}$ \\
\hline & & $\begin{array}{l}\text { Adding depth and } \\
\text { detail }\end{array}$ & $\begin{array}{l}\text { "We certainly built on our experience and told stories, if you will, } \\
\text { to the students about what you may see or may not see. They're } \\
\text { like, really?" }\end{array}$ \\
\hline & & Clinical & $\begin{array}{l}\text { "It made clinical a little easier, because we knew what the } \\
\text { students knew, and what the students knew was more organized, } \\
\text { so we could enhance student learning in clinical in a more } \\
\text { organized way" }\end{array}$ \\
\hline
\end{tabular}

As a result of the findings from survey and focus group of the pilot project, there were no major changes recommended. However, anecdotal information obtained from faculty teaching in the laboratory/clinical component of the pilot project indicated a need for more detailed outlines of the content covered in the classroom, information about the case studies and scenarios used in the didactic course, a list of the available skills videos, and recommendations for how to adjust their own teaching to accommodate the changes. 


\section{Evaluation of the full project}

Survey instruments were developed according to the processes described for the pilot project surveys. In addition, in the full project the surveys were offered to both students and faculty involved in the courses and additional items were included to assess specific competencies from the QSEN project ${ }^{[2]}$ and BSN Essentials document ${ }^{[12]}$.

\subsection{Results of the student survey}

Of the 126 students enrolled in the courses, 42 responded to the survey invitation, yielding a 33\% response rate. Most of the students were in the age category of less than 24 years old (36\%), female (88\%), and white (83\%). The student demographic information is presented in Table 2.

Table 2. Undergraduate Student Demographic Data

\begin{tabular}{lll}
\hline $\begin{array}{l}\text { Students (n= 42) } \\
\text { (33\% response rate) }\end{array}$ & $\mathbf{n}$ & $\%$ \\
\hline Age category & 15 & 35.7 \\
$<24$ & 8 & 19.0 \\
$25-29$ & 6 & 14.3 \\
$30-34$ & 7 & 16.7 \\
$35-39$ & 6 & 14.3 \\
$40-49$ & 0 & 0 \\
$50-75$ & & \\
Gender & 36 & 87.8 \\
Female & 10 & 12.2 \\
Male & & \\
Race & 35 & 83.3 \\
Caucasian/white & 1 & 2.4 \\
African American/black & 0 & 0 \\
Asian & 0 & 0 \\
Native American & 5 & 11.9 \\
Other & & \\
\hline
\end{tabular}

Most of the students who participated in the survey strongly agreed or agreed that the classroom content prepared them for the skills laboratory (76\%), and that the clinical scenarios were helpful (64\%). They also felt encouraged to be self-directed (88\%), thought the skills videos were helpful (79\%), and viewed most of the videos (58\%). The cultural competence project increased their knowledge (71\%) and helped them to recognize personal attitudes (60\%) about diverse groups. For more details about the results of the student survey, see Table 3.

Most of the students spent at least some additional time in the RCICNE on independent skills practice (83\%). See Figure 1 for a graphic display.

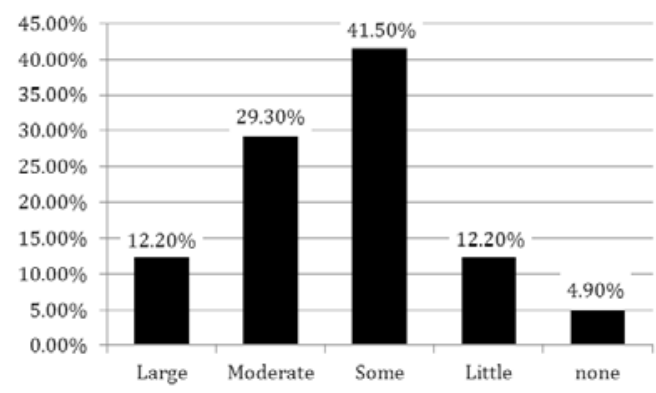

Figure 1. Additional Time Spent Practicing Skills 
Table 3. Results of the Student Surveys for Full Project

\begin{tabular}{|c|c|c|c|c|c|c|}
\hline Student survey $(n=42),($ range $=1-5)$ & $\begin{array}{l}\text { Strongly } \\
\text { agree }(\%)\end{array}$ & $\begin{array}{l}\text { Agree } \\
(\%)\end{array}$ & $\begin{array}{l}\text { Neutral } \\
(\%)\end{array}$ & $\begin{array}{l}\text { Disagree } \\
(\%)\end{array}$ & $\begin{array}{l}\text { Strongly } \\
\text { disagree } \\
(\%)\end{array}$ & Mean (\%) \\
\hline \multicolumn{7}{|l|}{$\begin{array}{l}\text { AIM 1: course congruence with a focus on } \\
\text { application in complex health care settings }\end{array}$} \\
\hline $\begin{array}{l}\text { found case study and clinical scenarios helpful } \\
\text { for applying classroom content }\end{array}$ & 22.0 & 41.5 & 31.7 & 4.9 & 0 & 3.8 \\
\hline $\begin{array}{l}\text { thought classroom content prepared them for lab } \\
\text { experiences }\end{array}$ & 14.3 & 61.9 & 14.3 & 9.5 & 0.0 & 3.81 \\
\hline \multicolumn{7}{|l|}{$\begin{array}{l}\text { AIM 2: self-directed and collaborative } \\
\text { learning }\end{array}$} \\
\hline $\begin{array}{l}\text { felt encouraged to be self directed in their own } \\
\text { learning }\end{array}$ & 26.2 & 61.9 & 9.5 & 2.4 & 0.0 & 4.12 \\
\hline thought videos assisted their learning & 23.8 & 54.8 & 16.7 & 4.8 & 0 & 3.98 \\
\hline viewed most or all of the videos & 48 & 9.5 & 38.1 & 47.6 & 4.8 & 2.52 \\
\hline felt prepared to go to clinical experiences & 14.3 & 66.7 & 16.7 & 2.4 & 0 & 3.93 \\
\hline \multicolumn{7}{|l|}{$\begin{array}{l}\text { AIM 3: experiences to integrate knowledge, } \\
\text { skills, and attitudes for professional role }\end{array}$} \\
\hline $\begin{array}{l}\text { thought the cultural project helped them to } \\
\text { recognized personal attitudes about working } \\
\text { with patients from diverse cultures }\end{array}$ & 16.7 & 42.9 & 19.0 & 14.3 & 7.1 & 3.48 \\
\hline $\begin{array}{l}\text { Found group cultural presentation increased } \\
\text { knowledge about caring for diverse cultures }\end{array}$ & 19.0 & 52.4 & 7.1 & 16.7 & 4.8 & 3.64 \\
\hline $\begin{array}{l}\text { valued seeing health care through the patients' } \\
\text { eyes }\end{array}$ & 61.9 & 38.1 & 0 & 0 & 0 & 4.62 \\
\hline
\end{tabular}

\subsection{Results of the faculty survey}

Of the twelve faculty members teaching the two courses, 7 responded to the survey invitation yielding a response rate of $58 \%$. The main findings from the faculty survey were that the skills videos facilitated faculty teaching (72\%) and were consistent with course materials (86\%). Most of the faculty believed that the new course enhancements increased the amount of time for skills teaching and practice (85\%) in the RCICNE, and improved student learning (71\%). The application of knowledge to practice situations using the unfolding case study was rated favorably by faculty (86\%). The time (57\%) and amount (86\%) of clinical practice opportunities were also rated highly. Faculty thought that course changes encouraged the students to be self-directed (71\%). Most of the faculty selected "neutral" in response to the questions assessing improvements in student's knowledge (69\%), skills (69\%), and attitudes (67\%) about professional nursing practice.

\section{Discussion}

The findings from this curriculum project, in which two foundational nursing education courses were enhanced to include recommendations from recent national initiatives, offer evidence that implementation is feasible, can be accomplished relatively quickly, and facilitate student achievement of the QSEN competencies. In addition, the enhancements were successful in achieving congruence between the courses, offered a greater focus on clinical application and opportunities for both self-directed and collaborative learning. 
There were three main themes that emerged from the faculty focus group data. First, faculty thought that because of the course changes students were "getting what they need". They also thought students were taking ownership, were better prepared, and that clinical application scenarios were helpful. Second, about "the way we taught then," faculty commented that it was difficult to cover the content and teach skills effectively within the allotted time. Last, faculty thought "the new way" offered more time for students to acquire psychomotor skills and for faculty to add important "depth and detail” to facilitate application to practice. A faculty member said, "It made clinical a little easier, because we knew what the students knew, and what the students knew was more organized, so we could enhance student learning in clinical in a more organized way".

Evaluation data from the faculty and student surveys indicated that the curriculum initiatives were rated positively with $57 \%$ to $88 \%$ of the participants rating most of the items as "strongly agree" or "agree". Moreover, $83 \%$ of the students spent at least some, if not more, time practicing skills independently. Although, no comparison data was available, anecdotal feedback from faculty indicated that significantly more time was spent practicing than in previous semesters. The largely neutral responses from faculty about improvements in student's knowledge, skills, and attitudes about professional nursing practice may be explained by the fact that the two courses had previously contained content to facilitate student acquisition of beginning competencies in nursing practice. Further investigation in this area is needed.

There are several limitations to the interpretation of these findings. First, although response rates from the three surveys averaged $44 \%$, higher than the expected average of $33 \%{ }^{[16]}$, there may have been response bias among those who chose to participate. Alternatives that may increase response rates include paper and pencil surveys, reminders, incentives, and discussions with students about the significance of their feedback ${ }^{[16]}$. Although the survey tools were designed in consultation with content experts and course faculty members, the validity and reliability had not been established. Also, there was no preliminary data from the previous courses that could be used as a comparison.

Future work in these courses will focus on building the unfolding case study to add more depth and detail, expanding the use of clinical context with task trainers, developing real-time simulations to facilitate a match between course objectives and available clinical experiences, using clicker technology in the classroom to promote critical thinking and group discussion, and improving methods to evaluate student learning and achievement.

\section{I mplications and conclusions}

There is a growing demand and expectation by healthcare consumers and providers for nurses to function, upon graduation, at an increasingly higher level. The impetus falls upon the schools of nursing to provide graduates who can function in a complex environment. Although the results of our project were specifically designed for our courses, nurse educators from other schools of nursing can benefit. Our experience with program revision can be used by schools of nursing in several ways. First, it can serve as a beginning point for discussion about a need for full curriculum revision or enhancement. Second, the information can be used as a template for course revision in situations where curriculum revision is not desired. Additionally, our report of course enhancement can be used for open discussion about any number of unique teaching techniques that could be incorporated into individual courses in any school. Further program evaluation projects and formal research about effective teaching techniques and strategies in professional nursing education is needed to inform and support work in this important area.

Future research designed to specifically measure changes in student knowledge, skills, and attitudes as a result of curriculum changes or other educational programs are strongly encouraged. Longitudinal research targeted toward measuring the effects of program changes on nursing graduates' performances in the clinical environment is also needed. 


\section{Competing interests}

The authors declare that they have no competing interests.

\section{Acknowledgements}

The authors would like to acknowledge consultants, Patricia Ebright, PhD, CNS, RN, FAAN and Janet Fulton, PhD, RN, ACNS-BC, FAAN who contributed to the overall conception and design of the project.

\section{Funding}

Indiana University School of Nursing and The Center for Teaching and Learning provided funding for the Principle Investigator, Susan M. McLennon.

\section{References}

[1] Institute of Medicine. Health professions education: A bridge to quality. Workshop Report [Internet]. 2003. Available from: http://www.iom.edu/Reports/2003/health-professions-education-a-bridge-to-quality.aspx.

[2] Cronenwett L, Sherwood G, Barnsteiner J, Disch J, Johnson J, Mitchell P, et al. Quality and safety education for nurses. Nurs Outlook. 2007; 55: 3, 122-131. PMid:17524799 http://dx.doi.org/10.1016/j.outlook.2007.02.006

[3] National Council of State Boards of Nursing. Models of effective programs that transition students to practice [Internet]. 2004. Available from: https://www.ncsbn.org/.

[4] Barton AJ, Armstrong G, Preheim G, Gelmon SB, Andrus LC. A national Delphi to determine developmental progression of quality and safety competencies in nursing education. Nurs Outlook. 2009; 57: 6, 313-22. PMid:19942032 http://dx.doi.org/10.1016/j.outlook.2009.08.003

[5] Tanner C. The next transformation: clinical education. J Nsg Educ. 2006; 45: 99-100.

[6] McNelis AM, Ironside P. In Clinical Nursing Education: Current Reflections. N. Ard, T. Valiga, eds. New York: National League for Nursing, 2009. PMid:19474428

[7] Gerrish K. Still fumbling along? A comparative study of the newly qualified nurse's perception of the transition from student to qualified nurse. J Adv Nurs. 2000; 32: 473-480. PMid:10964197 http://dx.doi.org/10.1046/j.1365-2648.2000.01498.x

[8] Heslop L, McIntyre M, Ives G. Undergraduate student nurses' expectations and their self-reported preparedness for the graduate year role. J Adv Nurs. 2001; 36: 626-634. PMid:11737494 http://dx.doi.org/10.1046/j.1365-2648.2001.02022.x

[9] Salyers VL. Teaching psychomotor skills to beginning nursing students using a web-enhanced approach: a quasi-experimental study. Int J Nurs Educ Scholarsh. 2007; 4: 1-12. PMid:17402927 http://dx.doi.org/10.2202/1548-923X.1373

[10] Oregon Consortium for Nursing Education [Internet]. 2008. Available from: http://www.ocne.org.

[11] Barkley EF, Cross PK, Major CH. Collaborative Learning Techniques: A Handbook for College Faculty. San Francisco: John Wiley \& Sons, 2005.

[12] American Association of Colleges of Nursing. The Essentials of Baccalaureate Education for Professional Nursing Practice. 2008. Available from: http://www.aacn.nche.edu/education-resources/BaccEssentials08.pdf.

[13] The Delphi method: Techniques and applications [Internet]. M. Turoff, H. Linstone, eds. 2002. Available from: http://is.njit.edu/pubs/delphibook/.

[14] Elo S, Kyngäs H. The qualitative content analysis process. J Adv Nurs. 2008; 62:107-15. PMid:18352969

[15] Krueger RA. Analyzing and reporting focus group results. Thousand Oaks: Sage, 1998.

[16] Nulty DD. The adequacy of response rates to online and paper surveys: What can be done? Assess Eval Higher Educ. 2008; 33: 3, 301-314. http://dx.doi.org/10.1080/02602930701293231 